\title{
Sábia dislexia. Magritte entre a similitude e a semelhança
}

\author{
STÉPHANE HUCHET
}

Stéphane Huchet é Professor Titular da Escola de Arquitetura da Universidade Federal de Minas Gerais. Pesquisador do CNPq, Bolsa em Produtividade. Membro do Comitê Brasileiro de História da Arte (CBHA). Pós-doutorado na França (supervisão Prof. Jean-Marc Poinsot, Université de Haute-Bretagne, Rennes II, 2008-09). Doutorado em História e Teoria da Arte, École des Hautes Etudes en Sciences Sociales (1990). Mestrado em Artes, Université de Paris I Panthéon-Sorbonne (1984). Graduação em História da Arte e Arqueologia, Université de Paris IV Paris-Sorbonne (1982) e em História, Université de Haute-Bretagne (1981). Publicou os seguintes livros: Fragmentos de uma Teoria da Arte, (Stéphane Huchet, org.) São Paulo: Edusp, 2012; Intenções Espaciais. A plástica exponencial da arte (1900-2000), Belo Horizonte: C/Arte, 2012; Castaño. Situação da Pintura, Belo Horizonte: C/Arte, 2006; Le tableau du monde. Une théorie de l'art des années 1920, Paris: L'Harmattan, 1999.

AFILIAÇÃO: Universidade Federal de Minas Gerais, Belo Horizonte, Brasil 
- RESUMO

Apresentado no Colóquio Iconologia[s] Leituras (2018), promovido pelo grupo de pesquisa Bureau de Estudos sobre a Imagem e o Tempo da UFMG, este artigo se ocupa das categorias "semelhança" e "similitude" na iconografia magrittiana problematizando, em sua leitura, a teoria da imagem subjacente à poética paradoxal do pintor René Magritte.

- PALAVRAS-ChAVE

Iconologia; semelhança; René Magritte

\section{ABSTRACT}

Presented at the Colloquium Iconologia[s] Leituras (2018), promoted by the research group Bureau de Estudos sobre a Imagem e o Tempo - UFMG, Brasil, this article is dedicated to the categories "similarity" and "similitude" in Magrittian iconography, problematizing in its reading, the theory of the image underlying the paradoxical poetics of the painter René Magritte.

KEYWORDS

Iconology; resemblance; René Magritte 
Um colóquio consagrado à "iconologia" estimula o historiador da arte a reler as "velhas" categorias da história da arte. A arte moderna ou contemporânea se mostrou fertil para reinventar-lhes novos usos. No contexto da arte moderna, a categoria de "semelhança" pode também justificar um uso renovado, como mostra um pintor doravante "clássico", porém ligado ao surrealismo: René Magritte.

Conhecemos sua pintura, seus rebus visuais, as justaposições de realidades heterogêneas, tanto do ponto de vista lógico quanto semiótico: quadros em que as palavras pintadas debaixo de uma fruta não lhe correspondem; quadros em que a definição de um objeto pintado e a identidade do mesmo objeto divergem; telas em que o rosto da mulher que se olha no espelho se reflete numa mancha preta; quadro em que o reflexo não mostra o que deveria representar... Por trás dessa poética paradoxal ${ }^{1}$, existe uma teoria da imagem. A iconografia magrittiana evolui entre duas polaridades declaradamente assumidas pelo pintor: a "similitude" e a "semelhança". Elas mantêm entre si estreitas relações de convergência e divergência. É nas suas conferências, nos seus textos de catálogos, nas suas entrevistas, que Magritte proporciona à palavra "semelhança" uma potente força crítica.

Magritte afirma que confundimos sempre a semelhança e a similitude. No texto de uma conferência feita no dia 11 de dezembro de 1959 na Académie Picard, em Bruxelas, Magritte afirma: "na medida em que duas identidades têm mais ou menos alguma similitude [...] na linguagem familiar [semelhança significa] ser como uma outra coisa." 2 Duas coisas que têm alguma identidade em comum parecem ser semelhantes. Ora, elas são apenas similares. Contrastando com a similitude, a semelhança não se reduz ao fato visual e semiótico da similaridade. Ela não é uma informação. Ela é um ato. Magritte declara que a semelhança "é um ato que só pertence ao pensamento." 3 Ela é, como veremos mais adiante, coincidência consigo mesmo. Ela tem um caráter ontológico, e não semiótico. Em soma, não se trata, na semelhança, de algo que "se assemelha a" ou "com" alguma coisa, mas, arriscando um neologismo, de algo que semelha.

Magritte fala muito da similitude, mas não é possível entender seu uso no pensamento do pintor sem remeter a uma outra categoria, baseada, ela, no funcionamento da linguagem. É a partir do mecanismo da "coincidência" linguística que podemos entender a similitude visual.

\section{A coincidência}

Num texto publicado em maio de 1954 no catálogo de uma exposição no Palácio de Belas-Artes de Bruxelas, chamado "O pensamento e as imagens"4, Magritte defende uma singular teoria do pensamento. Para Magritte, o pensamento mais pobre é aquele que procura coincidir com seus objetos. A "coincidência" remete ao funcionamento habitual da linguagem, a seu funcionamento normativo. A coincidência é a produção e a confirmação, na linguagem, de uma adequação entre a coisa e o espírito, as

\footnotetext{
${ }_{1}$ Em entrevista com Pierredon (1955), Magritte declara que sua pintura não é um enigma que pede uma solução. Ela cria uma imagem do enigma total e insolúvel do mundo. "Não consiste numa 'chave' que um autor obscuro escondeu cuidadosamente afim de tornar sua obra 'misteriosa' ou fantástica." In: MAGRITTE, René. Écrits complets. Edição estabelecida e anotada por André Blavier. Paris: Flammarion, 2009, p.409.

${ }^{2}$ MAGRITTE, René. “La ressemblance", in: Écrits complets, op.cit., p.493.

${ }^{3}$ Ibidem.

4 “La pensée et les images", in: Écrits complets, op.cit., p.374-376
}

ouvirouver Uberlândia v. 14 n. 2 p. 536-546 jul.|dez. 2018 
palavras e as coisas. Ela é fiel à tradição filosófica que, desde a Antiguidade, definiu a verdade como adequatio rei et intellectus (adequação da coisa e do inteleto). A coincidência exige uma ordem consciente da representação. É esse tipo de mecanismo que Magritte não considera como digno de ser chamado de pensamento.

Por trás da menção recorrente à coincidência, Magritte evidencia um mecanismo quase meta-psíquico presente na vida e na arte. Para tornar o mundo intelegível e habitável, precisamos que a linguagem se ajuste ao real, que ela se acorde com seu objeto, Ihe corresponda - a coincidência é uma correspondência. O senso comum declara que um mundo em que a linguagem e a realidade não se ajustariam seria inabitável. Ele seria um mundo de desajustes, de desestabilização constante, de dis-funcionamentos eventualmente enloquecedores. Por que Magritte está interessado na coincidência? Porque ela remete a um certo funcionamento da linguagem e da nossa mente. É isso que, na ordem da imagem, sua pintura trabalha, investe, explora, desloca, subverte, reverte. $\mathrm{Na}$ ordem da mimesis, as tensões semióticas entre elementos iconográficos tentam perturbar o jogo tradicional da coincidência (jogo sobre o qual a representação clássica fez repousar o essencial de seu sentido). Poderíamos afirmar que Magritte perturba o agenciamento das coincidências, suvertendo um velho princípio da arte clássica, o princípio de verosimiIhança (vero-similhança, istó é, etimologicamente, a verdade do similar, do simulado, como também da imaginação). De Alberti, no século XV, até o academicismo do século XIX, os ajustes sintáxicos, as correspondências e coincidências entre ordens do saber, a verosimilhança da estória etc., foram princípios norteadores da narrativa pictórica. O princípio de verosimilhança era fundamental na representação e na dramaturgia clássicas. Ele conseguia criar as condições de integração da ideia e do sentimento com a imagem que lhe correspondia, oferecendo ao espectador um universo proporcional a seus recursos mentais e culturais. A coincidência visual e a verosimilhança narrativa ou dramática garantiam a legibilidade da obra, a manifestação e transmissão de sua "mensagem". Durante milênios, a arte dedicou a maioria de suas imagens a uma vasta exploração das coincidências. Magritte não as despreza, como vamos ver, mas ele quer ir além. Deslocando esse conceito mais lógico de coincidência para o mundo visual, Magritte chama atenção sobre sua dimensão icônica. A imagem da coincidência é agora a "similitude".

\section{A similitude}

A pintura de Magritte toma o caminho da similitude, desposa sutilmente o jogo da coincidência entre imagem e referente - todo elemento pintado, num primeiro nível de informação, é o que é, isto é, a nuvem é nuvem, o pássaro é pássaro, o corpo é corpo, o cachimbo é cachimbo, a janela é janela - , mas é apenas um passo para entrar na desorientação. Na pintura de Magritte, bem no momento do tangenciamento com a similitude, a montagem incongruente de tudo o que permanece visualmente identificável faz explodir friamente a coincidência. Em suas imagens, tudo é identificável; entretanto, nada se encaixa numa possível síntese simbólica. Nunca saberemos de que se trata. É uma mimesis plenamente direcionada para a desorientação, uma mimesis da desorientação e uma desorientação da mimesis. 
No catálogo da sua exposição na Galerie Rive Droite, em Paris, em fevereiro de 1960, Magritte fala da "imagem de um pensamento que se assemelha ao mundo." 5 Mas, como entender o mundo?: como o conjunto dos fenômenos ou dos fatos que ocorrem. "A semelhança só apreende figuras tal como elas aparecem no mundo"6, acrescenta Magritte. Essa frase afirma a necessidade de jogar com as similitudes: trata-se bem de "se submeter à descrição exata do mundo visível"7 para garantir, num primeiro momento, a legibilidade da imagem. Magritte não está interessado pela abstração. Ele quer territorializar a experiência espiritual da semelhança dentro de um mundo fiel às aparências figurativas. Magritte é um pintor de feição acadêmica que revoluciona a academia. Introduz, na grande ciência da pintura, um jogo paradoxal e fascinante. Sua poética das (dis)similitudes, como ironia, não contesta, portanto, a necessidade de se manter fiel à ciência tradicional da pintura, como ciência das similitudes. A pintura de Magritte apresenta ainda espelhos, corpos, chapéus, ternos, casas, chaminés, quartos, janelas, plantas, flores, rochas, nuvens, noites, luz e sol etc. Magritte escreve em 1958:

É bem o mundo 'habitual' que as coincidências afirmam: elas garantem que as reconhecemos mais nitidamente. Em vez de se surpreender com a existência supérflua de um outro mundo, o que não devemos perder de vista é o nosso único mundo, em que as coincidências nos surpreendem. ${ }^{8}$

Para surgir, a futura semelhança precisa de uma iconografia paradoxal que possa gerar um choque semiótico através de um uso sistemático de signos identificáveis por todos. Magritte insiste - e nós com ele: "de um lado: semelhança só pertence ao pensamento, e, de outro lado: uma imagem pintada só tem similitudes possíveis com aspectos do mundo visível."9 Está dito. Trata-se de um grande "Sim", paradoxal, um "sim" ao mundo, mas num uso estratégico que abre a caixa de Pandora do estranhamento: o "dis" que vem perturbar a similitude, dis-similitude. Poderíamos dizer, pensando no modelo da retórica antiga - que inspirou os primeiros momentos da teoria renascentista da arte -, que a pintura de Magritte nos apresenta letras ( $a$ é a, b é b, c é c) ou ainda palavras. Porém, a frase da imagem soa, ela, incongruente, divergente: ela desmembra o enunciado. É um jogo frio de des-membramento dia-bólico, na verdade, mas que passa por uma fidelidade icônica total, num primeiro nível de leitura, à recogniscibilidade dos objetos. É uma sábia dislexia. Férias de Hegel, mesmo.

A dis-similitude é uma estratégia fina, uma ironia com verniz, sem desvios nem excessos, uma iconografia perfeitamente controlada, sem derrame de expressão emocional, sem saltos gritantes no pulsional, mas, ao mesmo tempo, a imagem magrittiana parece ser totalmente sintoma. O sintoma não é algum traço solto e desatado de alguma raiz intencional do pintor ${ }^{10}$ : ele é toda a imagem. Se tiver alguma loucura, ela passaria por uma espécie de irônico afeto de frieza. Espécie de suspensão cegante. Suas telas dizem: uso as mesmas palavras que vocês, mas

\footnotetext{
5 “L’art de peindre...", in: Écrits complets, op.cit., p.510.

${ }^{6}$ Ibidem.

7 Ibidem.

8 "Nature et mystère", in: Écrits complets, op.cit., p.467.

9 "La ressemblance", in: Écrits complets, op.cit., p.494.

10 Didi-Huberman reparava em pinceladas e manchas de pinturas do Angelico ou de Vermeer sintomas pictóricos, fendas pelas quais a pintura gritava, solta, sua autonomia a-semântica. Diante da imagem. São Paulo: Ed34, 2013.
} 
não digo nada do que vocês esperam. Enuncio coisas incompreensíveis... A pergunta que se apresenta agora é: como se passa da informação visual, do tensionamento dos signos (a dis-similitude) ao ato do pensamento que a semelhança é?

\section{A semelhança}

Tal é a lógica: o "sim" a nosso único mundo visa integrar as identidades descritas num mecanismo que revele sua proveniência na "ordem do mistério"11. A perturbação das similitudes possibilita que o mistério da semelhança inobjetiva passe, e perpasse a imagem. Como diz Magritte, trata-se ainda de "estender cores sobre uma superfície [mas] de tal maneira que seu aspecto efetivo [grifo nosso] se afaste e deixe aparecer uma imagem da semelhança." 12 A similitude, perturbada, acaba por se apagar para deixar transparecer a semelhança que ela mascarava... A pintura magrittiana faz seus signos brilharem numa luz que se auto-apaga para se redimir (se suprimir-conservar) e promover a imagem como medium de uma experiência espiritual e imaterial. Na similitude, trata-se de uma "ordem na qual o familiar e o estranho são restituídos ao mistério." ${ }^{13}$ A restituição estranha do familiar ao mistério cria as condições para a aparição da semelhança. Aparição, uma palavra da tradição fenomenológica, tanto hegeliana quanto husserliana (Scheinen. Erscheinen): brilhar, aparecer numa certa luz, certa luminiscência. Se a restituição ao mistério é uma condição para retirar as similitudes de sua subserviência semiótica, liberando nelas uma potência de transfiguração - a semelhança -, podemos considerar que Magritte não podia inventar universo mais adequado... Mas, como a semelhança aparece ou surge? Magritte nos dá a chave da resposta quando ele diferencia duas perguntas. Vejamos.

Para Magritte, a pergunta certa sobre suas pinturas não deve ser: "o que representa este quadro?", mas uma pergunta mais complexa, que implica, inclusive, um jogo e uma substituição gramaticais inéditos. A pergunta certa é: "quem representa este quadro?", ou melhor dito, "qual quem representa este quadro?" ou, distorcendo a gramática, "o quem representa este quadro?", tradução quase impossível do francês que pergunta: "qu'est-ce qui représente le tableau?" e não "qu'est-ce que représente le tableau?", que é a pergunta normal. A diferença entre "que" e "quil, entre "(o) quê" e "(o) quem?" é a diferença que existe entre a alusão a um objeto representado e a alusão a um sujeito cuja percepção é, deveras, uma construção da imagem pintada e não mais uma assimilação de uma informação iconográfica. A declaração de Magritte é singular. Ele declara em 1958:

Aquele que olha representa o quadro. Suas ideias e seus sentimentos representam o quadro. [...] É a partir de uma imagem pintada que ideias ou sentimentos podem aparecer e encontrar esta imagem. Uma imagem pintada não representa ideias ou sentimentos, mas ideias e sentimentos podem representar uma imagem pintada. ${ }^{14}$

\footnotetext{
$\overline{11}$ "L’art de peindre...", in: MAGRITTE, René. Écrits complets, op.cit., p.510.

12 Ibidem.

13 Ibidem.

14 "René Magritte met l'image au point", in: MAGRITTE, René. Écrits complets, op.cit., p.462
} 
Existe, na pessoa do observador, quem representa o quadro. "É aquele que olha o quadro que $(\mathrm{m})$ representa o que ele vê." ${ }^{15} \mathrm{~A}$ imagem adquire consistência $\mathrm{e}$ espessura naquele que a olha. É um ponto fundamental para entender a lógica que sustenta a teoria da semelhança de Magritte. Entretanto, o raciocínio vai mais longe. Magritte apresenta uma teoria surpreendente. Na conferência do ano 1959 na Académie Picard, ele propõe sua definição da semelhança como processo de conhecimento. "Ressembler" (semelhar) ${ }^{16}$

pertence ao pensamento. [...] é tornar-se a coisa que se leva consigo. Só o pensamento pode se tornar a coisa que ele toma consigo. Essa coisa se chama conhecimento. O nascimento do pensamento é o pensamento que se constitui ao tomar consigo um conhecimento, isto é, tornando-se conhecimento imediato. ${ }^{17}$

Magritte tinha um interesse evidente na filosofia. Menciona e alude inúmeras vezes a Hegel, Bergson, Merleau-Ponty, Heidegger, que ele tinha, inclusive, pensado convidar, em 1954, para responder a um questionário. Leu também Michel Foucault. Numa carta datada do dia 23 de maio de 1966, na época em que Magritte lê As palavras e as coisas, recém publicado, o pintor resume sua posição:

as 'coisas' não têm entre elas semelhança, elas têm ou não similitudes. Pertence tão somente ao pensamento ser semelhante [o que eu traduzo por semelhar]. Ele semelha [em vez de "parece"] com o ser que ele vê, escuta ou conhece, ele se torna o que o mundo lhe oferece. Ele é tão invisível quanto o prazer ou a pena. ${ }^{18}$

Semelhança significa auto-construção do pensamento através daquilo que

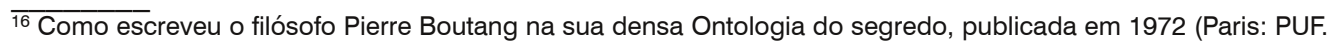
Col. Quadrige, 1995), "s'il existe de l'image qui ressemble, c'est donc qu'il y a de la ressemblance" (se existe imagem que parece com [que (se) assemelha (a)], existe, portanto, semelhança). A semelhança não é a repetição. A repetição, ela, reenvia a uma aparência-referência separada. A semelhança não segue a ideia de reprodução. A semelhança é de essência, e não de aparência. Segundo Boutang, a fórmula verbal que diz: "il semble que" ("parece que") seria, inclusive, o sintoma de um enfraquecimento linguístico da verdadeira semelhança que nunca "parece com". A semelhança não cria similitudes com alguma coisa. A semelhança é. Ela não atesta algum parentesco provável entre uma coisa e outra. Dizer "parece que", é afimar alguma margem de incerteza e distância. A semelhança, por sua vez, funciona numa espécie de área impessoal que lembra a função do ele (o "il”) em Blanchot, ou algum incorporal, de tipo deleuziano. Para retomar o exemplo proposto por Gilles Deleuze na "2a série..." da Lógica do sentido, em que faz eco ao denso estudo de Emile Bréhier sobre o incorpóreo no estoicismo, quando a árvore verdeja, o processo do verdejar não remete a uma instância mensurável ou ponderável. O verdejar remete a um processo-ocorrência que é um mecanismo metamórfico da árvore que verdeja imperceptível e gradativamente, sem possibilidade de medição e pausas calculáveis e identificáveis no processo do verdejar. Assim, quando chove, o que chove? A chuva? A chuva chove? Não. Qual é o artigo ou o sujeito de "chove"? Alguma instância neutra, distribuída em toda a intensidade do processo, é o agente do processo. Estou lembrando essa dimensão filosófica da semelhança para justificar que criemos um neologismo, que seria "semelhar", para diferenciar do "assemelhar-se". Na Antiguidade, existia, assim, a palavra "cosmear", fazer-cosmos, quando, através de sua beleza e de sua segunda pele "cosmética", a mulher grega encarnava uma participação cósmica à harmonia do universo. A mulher "cosmeava", e só ela. O "cosmear" da mulher era a participação ontológica dela à Natureza. "Semelhar" seria, no meu ver, uma forma de participação ontológica possivelmente propiciada pelas imagens, se seguirmos Magritte

17 "La ressemblance", in: MAGRITTE, René. Écrits complets, op.cit., p.493.

18 LMAGRITTE, René. Écrits complets, op.cit., p.639. Interessa ver como a semelhança tem o mesmo teor de invisibilidade que a pena ou o prazer, que constituem, sabemos, duas polaridades da experiência estética privilegiadas pela Estética filosófica na sua fase inicial, no século XVIII.
\end{abstract}


se conhece, isto é, aquilo em que o pensamento se trans-muta imediatamente. $\mathrm{Na}$ experiência da semelhança, nos tornamos a coisa que levamos conosco, em nosso interior mais íntimo. A imagem é matriz dessa trans-mutação. É a imagem que transforma o que vejo em meu pensamento e é a imagem que permite que minhas ideias e que meus sentimentos se transformem, reciprocamente, em imagem de pensamento, do meu pensamento. (Trata-se de algo em conformidade com a definição mais tradicional e etimológica do conhecimento: nascer com; (re)nascer com aquilo em que me trans-formo; incorporar o que conheço ou incorporar-me àquilo que conheço. A semelhança decorre da integração espaco-temporal i-mediata entre pensamento e conhecimento.)

\section{Visão de pensamento}

Não diz respeito à percepção, mas a alguma coisa que eu chamaria de visão de pensamento. $\mathrm{Na}$ frente de La condition humaine ou de L'image parfaite, eu vejo meu pensamento e meu pensamento pensa sua visão; vejo minha visão e penso meu pensamento. Chiasma simbólico. A distância tradicional entre imagem e olhar é transposta. $\mathrm{O}$ apagamento da distância inerente a toda representação define a semelhança-pensamento como advir integral naquilo que é visto. Ou meu devir integral naquilo que vejo. $\mathrm{O}$ que Magritte chama de pensamento ocorre quando a semelhança supera as distâncias físicas e semióticas que impediam ainda uma integração total entre o espírito e a imagem. Magritte é claro quando ele fala de sua pintura:

Diante dessas imagens que mostram tudo o que elas são, em que nada é escondido, o pensamento é responsável daquilo que ele pensa, conquanto não se furte recorrendo a uma "interpretação alegórica", isto é, ao hábito de propriamente não ver nada. ${ }^{19}$

Quando a distância entre imagem e olhar é diluida por um mecanismo de integração mútua, o sujeito não está mais situado no mundo da percepção, mas da visão de uma "quidditas" espiritual. Magritte já afirmava em 1954:

Pensar numa imagem significa Ver uma imagem. O quadro representa uma imagem sensível ao sentido da visão. O sentido da visão registra a imagem apresentada pelo quadro sem Ver, ao avesso, conforme as leis da óptica e como uma câmara fotográfica. No pensamento, essa imagem se torna uma imagem moral, isto é, uma imagem tendo um valor espiritual. ${ }^{20}$

Magritte, aqui, recicla uma noção que costumamos associar ao romantismo: a inspiração ("uma ideia magnífica que aparece de repente no pensamento. [...] a descoberta fortuita de um possível que convem a um modo de pensar" ${ }^{21}$ ). A arte

\footnotetext{
19 “"La pensée et les images”, in: Écrits complets, op.cit., p.380.

20 lbidem. p.374.

${ }^{21}$ Ibidem. 'L'art de peindre...", in: Écrits complets, op.cit., p.513
} 
que visa a semelhança movimenta uma inspiração. Magritte a define como "o evento em que o pensamento [é] a própria semelhança"22, o que eu definiria como uma mimesis radical, que devolve todo o processo perceptivo a uma instância mais imponderável que tento definir através da fórmula: sou o que vejo, vejo o que sou. "O espectador deve ver essas imagens em plena Liberdade, ver o que elas são: elas são SEU pensamento do Sentido", afirma Magritte no texto do catálogo da exposição em La Louvière, em março de 1954.

A iconicidade da imagem magrittiana, parece sempre suspender o tempo, apresentar um tempo suspenso, eternizar o estar-aí, congelando as paixões. A evidência eterna, A condição humana, A imagem perfeita, são títulos lentos, graves, na demora do ser, no cerne do ser, A reprodução proibida, O império das luzes, A máscara vazia, $O$ falso espelho, $A$ traíção das imagens. São títulos que programam um lento pensar... Ao mesmo tempo, a iconicidade magrittiana inverte o lento para lançar mão de uma estética do surgimento súbito e indomável de um clarão interior. Títulos reflexivos, títulos metafísicos... O sentido da imagem magrittiana é indomável porque não se doma o insight ou o flash do pensamento, já que ele não é objeto, mas plena intuição. Insight ou flash que surge, irrompe, projeta seu cintilamento. É a razão que incendeia a razão. Friamente, lentamente, iconicamente, numa ataraxia paradoxal, se isso existir. Magritte é um pintor do oxímoro. E é esse mistério instantâneo, abrupto, simplesmente complexo, esse screen impenetrável que Magritte transforma em condição da presença. Como afirma Magritte, na arte submetida à semelhança, "a inspiração não surge, senão na condição necessária de sua presença"23. Essa presença é chamada por Magritte de "incondicional", um "incondicionado" - que o artista deve fazer funcionar e disparar no imaginário. Por pouco, poderíamos definir em termos metafísicos essa imagem que inspira, que faz surgir meu pensamento da visão, como uma graça suplementar que se manifesta para mim e em mim como imagem imanente. É exatamente este momento em que nasço a meu próprio pensamento da imagem, meu próprio pensamento da visão. É precisamente uma experiência da presença, a presença plena a si mesmo, e não mais uma representação.

Para Magritte, transcender as correspondências e coincidências permite que "os objetos representados existam no quadro para todo mundo"... Repito em itálico: que os objetos representados no quadro existam para todo mundo. O que isso significa? Que a impossível decodificação das imagens é uma liberação, uma liberação para o espectador. Este último não precisa mais solicitar uma bagagem cognitiva prévia, já que a imagem magrittiana não almeja satisfazer uma demanda no nível da representação verossímil. A pintura magrittiana, liberando o espectador desse trabalho tradicional, faz com que, de certa maneira, é o espectador que faz o quadro e que cria a semelhança que lhe é própria. Esse processo só pode acontecer na imagem e com a imagem, para que meu pensamento surja como imanência icônicoespiritual. A imagem-semelhança é esse topos singular, icônico-espiritual, em que a “inspiração", reivindicada por Magritte, se torna respiração. No conhecimento que a imagem faz surgir, encontro minha própria produtividade estética, minha própria produtividade simbólica, minha própria maneira de nascer não só ao quadro, livremente, mas a mim mesmo. Notemos que o "belo" kantiano tinha esse caráter de

\footnotetext{
22 "La ressemblance", in: Écrits complets, op.cit., p.495.

23 Ibidem.

ouvirouver Uberlândia v. 14 n. 2 p. 536-546 jul.| dez. 2018
} 
auto-construção, de, pelo prazer tomado à relação com o objeto, fazer o sujeito experimentar uma forma de auto-edificação que harmoniza as faculdades, que reconcilia algo de mais íntegro e total. Ora, se a pintura magrittiana é uma imagem de pensamento, a experiência que dela se tem é construtiva e edificadora: o salto imediato no mistério restitui o espectador ao mistério de sua sensibilidade, de sua vida, não só interior, à sua faculdade de invenção e, de certa maneira, de (re)criação. Tal é a semelhança. Uma maneira de advir à minha própria criatividade espiritual. A inspiração, dessa vez, está do lado do espectador, e não apenas do artista. "A inspiração, escreve Magritte, é um acontecimento não familiar, absolutamente necessário para que o pensamento seja a própria semelhança." ${ }^{24}$ A semelhança alça o espectador no nível de uma nova coincidência, de uma nova correspondência. O espectador vê o que as imagens são: seu próprio pensamento do sentido. A poética magrittiana do mistério apaga as certezas ou as referências pré-existentes e libera para uma experiência quase absoluta do "Valor", que Magritte define como "o Sentido" no catálogo da exposição no Palácio de Belas Artes de Bruxelas, em maio de 1954. O espectador faz o quadro porque o transforma naquilo em que se torna quando ele o toma consigo na aventura da visão, mas uma visão inteletiva que se torna presença "do ser"... A visão que semelha cria a verdadeira coincidência, aquela que o espectador inventa para si. Magritte chama isso de "pensamento moral do Impossível", ou, ainda, "a coisa enquanto tal"25. Seria ela uma esfera?

Magritte, vocês já observaram, pintas muitas formas redondas. Em Esferas, o filósofo Peter Sloterdijk apresenta uma fascinante meditação sobre a nossa condição na primeira esfera da nossa vida, o foetus materno. Desde os primeiros momentos intra-uterinos, nossa vida sensorial começa através da escuta da voz maternal que ressoa, fibrilar, nas espessuras do plasma. Aqui, eu ousaria interpretar o não-interpretável: $O$ quarto de escuta, $A$ descoberta do fogo, são, quiçá, a melhor imagem do poder da esfera, câmara acústica em que a música, quando soa e ressoa, vibra. O pensamento-semelhança é a revelação íntima daquilo que a imagem pode veicular, uma potência invisível que queima as aparências para fazê-las vibrar. Quando o som vira chama. Quando a maçã-monumento, fisicamente absurda, revela na sua (dis)similitude o eco interior que agita todo tímpano, no meu ouvido, como também faziam os portais das basilicas que os românicos criaram para ouvir o Apocalípse. Como afirma Magritte num manuscrito, "não há nada a dizer da pintura, senão for para entender o que escutamos." 26

Findemos este artigo com uma citação do parágrafo 95 do Livro do filósofo, de Nietzsche. Afirma ele: "o pensamento nos propicia o conceito de uma forma toda nova da realidade. O homem no mundo poderia realmente se conceber como alguma figura saida de um sonho e que sonha, ao mesmo tempo, com si mesmo."27

Recebido em 18/10/2018 - Aprovado em 30/10/2018

\footnotetext{
$\overline{24}$ Ibidem.

25 "La pensée et les images", in: Écrits complets, op.cit., p.376.

${ }^{26}$ Indicado como manuscrito, in: Ibidem, p.377.

27 NIETZSCHE, Friedrich. Le livre du philosophe. Trad., introd. e notas por Angèle k.Marietti. Paris: AubierMontaigne, 1969, p.105.
} 
Como citar:

HUCHET, Stéphane. Sábia dislexia. Magritte entre a similitude e a semelhança. ouvirOUver; Uberlândia, v.14,n.2, p.536-546 jul./dez. 2018. Disponível em:

http://www.seer.ufu.br/index.php/ouvirouver; DOI:http://doi.org/10.14393/OUV23v14n2a2018-20

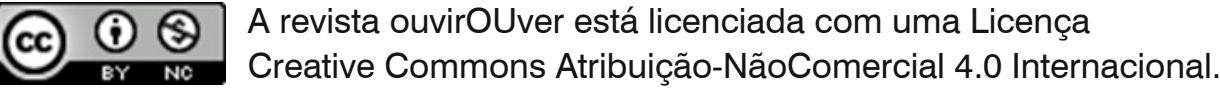

